\title{
59 \\ The future of integrated network and systems management
}

\author{
Yogesh GUPTA, Senior Vice President, Computer Associates, \\ U.S.A.
}

The issue of managing distributed systems and networks has recently received enormous attention. End-to-end management of the enterprise computing infrastucture has become the mantra of IT managers. With the growth of the Internet, management from anywhere is becoming a reality. However, the ultimate goal is to achieve selfmanaging and self-tuning networks and systems.

This talk will discuss the current state of the industry with respect to integrated network and systems management and what the future holds. Topics covered include the issues and challenges faced by network and systems managers, the evolution and impact of relevant technologies and standards, the state of the current crop of commercial products and direction in which they are evolving. 